\title{
Etnomatemática na formação do professor de matemática: uma experiência construída no âmbito do PIBID
}

Ethnomathematics in the training of mathematics teacher: an experience built within the scope of PIBID

\author{
Lucélida de Fátima Maia da Costa ${ }^{1}$ \\ Gênneton Reis Lopes ${ }^{2}$ \\ Glefini Elias Glória ${ }^{3}$ \\ Kitéria Costa Brito ${ }^{4}$
}

\section{Resumo}

Nesse texto apresentamos o relato de uma experiência construída no desenvolvimento de uma atividade prática no âmbito de um subprojeto do Programa Institucional de Bolsas de Iniciação à Docência - PIBID, denominado Matemática em Foco 2. Desde seu planejamento até sua efetivação em sala de aula, a atividade realizada foi fundamentada nos princípios da Etnomatemática como tendência da Educação Matemática e teve duração de três semanas. O objetivo da atividade consiste em propiciar aos futuros professores experiência docente aliada ao diálogo entre saberes da tradição e saberes escolares. Participaram da atividade uma coordenadora de área, três bolsistas e doze alunos selecionados pelo professor da turma por apresentarem dificuldade no trabalho com progressão aritmética. A atividade foi desenvolvida em uma escola estadual localizada em um bairro periférico da cidade de Parintins-AM. Os resultados obtidos nos permitem dizer que a Etnomatemática, na formação de professores, contribui para o alargamento da visão que construímos de matemática podendo ser entendida como uma janela cultural para olharmos a matemática e pensarmos a prática docente.

Palavras-chave: Formação de professor. Educação Matemática. Etnomatemática. PIBID. Progressão aritmética.

\footnotetext{
1 Doutora em Educação em Ciências e Matemáticas - área de concentração em Educação Matemática, professora do Colegiado de Matemática da Universidade do Estado do Amazonas, no Centro de Estudos Superiores de Parintins, lucelida@uea.edu.br

${ }^{2}$ Licenciando em Matemática pela Universidade do Estado do Amazonas, bolsista do PIBID no Centro de Estudos Superiores de Parintins, gennetonreislopes@gmail.com

${ }^{3}$ Licencianda em Matemática pela Universidade do Estado do Amazonas, bolsista do PIBID no Centro de Estudos Superiores de Parintins, glefinielias@gmail.com

${ }^{4}$ Licencianda em Matemática pela Universidade do Estado do Amazonas, bolsista do PIBID no Centro de Estudos Superiores de Parintins, kcbrito.21@gmail.com
} 


\section{Introdução}

A formação de um professor de matemática congrega teoria e prática. Embora, muitas vezes, não sejam exercitadas na mesma proporção, se constituem os alicerces da aprendizagem de futuros professores.

Com o objetivo de propiciar a articulação entre teoria e prática durante a formação de futuros professores e visando elevar a qualidade das ações acadêmicas nos cursos de licenciatura, o Programa Institucional de Bolsas de Iniciação à docência - PIBID viabiliza o desenvolvimento de projetos que inserem os licenciandos no ambiente escolar para serem iniciados na profissão sob a orientação de professores tanto da universidade quanto da escola.

No âmbito do desenvolvimento de um subprojeto do PIBID, denominado Matemática em Foco 2, nos pautamos nos princípios da Etnomatemática para desenvolver com três bolsistas uma atividade de ensino de matemática para alunos do $1^{\circ}$ ano do Ensino Médio, que evidenciavam dificuldade na compreensão da definição de progressão aritmética, seus elementos e características, em uma escola estadual localizada num bairro periférico da cidade de Parintins-AM.

A motivação para o desenvolvimento da atividade pautada nos princípios da Etnomatemática decorre do pressuposto que a forma como a matemática é trabalhada nas salas de aula, nos diferentes níveis da escolarização, pode contribuir para o desgosto e muitas das dificuldades expressas pelos alunos em relação a matemática. Optamos pela Etnomatemática porque, como tendência da Educação Matemática, propicia ao professor o desenvolvimento do ensino de conteúdos matemáticos de modo contextualizado em processos, ações, elementos e produtos socioculturalmente elaborados. (D'AMBROSIO, 2013).

Ações e estudos etnomatemáticos valorizam saberes "matemáticos" que não estão presentes no currículo escolar, mas que estão "no cotidiano das pessoas, das práticas profissionais, de grupos culturalmente identificáveis", sem se contrapor à matemática escolar, pois a considera uma das matemáticas 
existentes, e que "merecem ser compreendidas e difundidas em atendimento aos grupos que se interessam por elas". (LUCENA, 2012, p. 13).

Nessa perspectiva, na elaboração da atividade desenvolvida, a história de vida e a experiência cultural em uma comunidade ribeirinha de um dos bolsistas foi determinante para a definição das estratégias de ensino, isso porque nos preocupamos não apenas com o aspecto quantitativo do ensino, mas também com o sentido e os significados que nossa prática docente pode desencadear. Assim, definimos que a atividade partiria de um diálogo com os alunos sobre um objeto muito comum na região amazônica, o paneiro.

O paneiro é um produto cultural de raízes indígenas que, pela proximidade, convivência e utilidade foi incorporado à dinâmica de vida de povos ribeirinhos da Amazônia. O processo de confecção de um paneiro expressa uma trama complexa na qual podemos identificar ideias matemáticas que podem constituir referências, contexto, para 0 ensino de objetos matemáticos presentes no currículo escolar. (COSTA, 2009).

O planejamento da atividade contemplou o estudo do conteúdo matemático, momentos de reflexão sobre o ensino da matemática, sobre a Etnomatemática e a formação do professor e a prática docente. Do planejamento à realização da atividade foi necessário um trabalho de três semanas para que os bolsistas aprendessem a tecer um paneiro, para definirmos as estratégias e elaborarmos os questionamentos que serviram de fio condutor para o processo de ensino e de aprendizagem do objeto matemático mediado pela confecção de um objeto cultural.

\section{A importância da Etnomatemática na formação de um professor de matemática}

Formar-se professor é um processo contínuo. Não nos tornamos professor simplesmente por concluirmos um curso de licenciatura, que é um requisito fundamental, necessário, mas não suficiente; pois ser professor requer reflexão constante sobre os objetivos e as ações docentes realizadas. Nessa direção, 
pensamos que a formação de um professor não deve ignorar que "a matemática é um produto da atividade humana cuja evolução está relacionada à resolução de problemas ao longo dos tempos" (TAVARES; COSTA, 2015, p. 4). Por assim ser, sua apresentação no contexto escolar (em todos os níveis) não deve ocorrer de forma asséptica de uma realidade.

Nessa linha de pensamento, nos pautamos nos princípios da Etnomatemática para trabalharmos a formação do professor de matemática reconhecendo que toda a matemática sistematizada e ensinada nos cursos de formação de professores, nas licenciaturas, em maior ou menor grau, deriva de situações onde diferentes decisões foram tomadas condicionadas por diferentes padrões socioculturais (DOMITE, 2012). Isso é o que mostra a história da matemática.

A formação de um professor de matemática pode incentivar o questionamento "sobre a relação existente entre os nossos conhecimentos e valores e os dos outros, de outras comunidades educacionais, consideradas no seu sentido mais amplo" (DOMITE, 2012, p. 87), para que possamos ao longo dessa formação estabelecer relações entre as diferentes formas de se matematizar desenvolvidas pelo homem em diferentes contextos socioculturais.

O processo de formação de um professor, particularmente, de matemática deve propiciar experiências e reflexões que permitam ao licenciando perceber que "a mitificação do saber matemático, reforçado pelos testes e exames rotineiros, é a maior causa de negar ao povo o importante instrumento de crítica proporcionado pela Matemática" (D’AMBROSIO, 2012, p. 59) e que a prática docente pode contribuir para reforçar ou enfraquecer essa negação.

No âmbito das tendências da Educação Matemática, "a Etnomatemática é a que mais se aproxima de uma prática que questiona o universalismo da matemática ao mesmo tempo em que procura valorizar conhecimentos matemáticos de distintas culturas" (SOUZA; COSTA; ALMEIDA, 2011, p. 162). Torna-se, assim, uma perspectiva educativa possível de ser adotada na formação de um professor de matemática, pois partimos do pressuposto que o ensino deve 
ter como referência a realidade cultural na qual a escola está inserida e valorizar os conhecimentos matemáticos empíricos que os alunos trazem consigo.

No âmbito das tendências da Educação Matemática, a Etnomatemática traz

Uma nova visão de matemática e de educação matemática de feição antropológica, social e política, que passam a ser vistas como atividades humanas determinadas socioculturalmente pelo contexto em que são realizadas. A Matemática, por exemplo, só adquire validade e significação no interior de um grupo cultural [...] onde se encontra presente nas diferentes práticas socioculturais. (FIORENTINI, 1995, p. 25).

Daí a importância de serem trabalhadas, na formação inicial, estratégias de ensino que permitam ao futuro professor experienciar um diálogo entre o ensino da matemática escolar e os saberes "matemáticos" culturalmente validados de modo a ampliar sua percepção, entendimento e valorização dos conhecimentos construídos em diferentes realidades culturais, pois estes podem contribuir para 0 alargamento dos referenciais cognitivos que influenciam a aprendizagem matemática.

Uma formação nessa direção pode propiciar aos futuros professores o desenvolvimento de habilidades para reconhecer ideias, processos e práticas "matemáticas" sociocultural mente estabelecidas que podem se constituir contexto para atividades matemáticas em sala de aula se afastando assim, da nefasta ideia, ainda, impregnada em muitos processos de formação docente onde

A construção de vínculos substantivos da formação com a prática é vista como uma tarefa a ser executada basicamente no exterior da formação matemática. A esta caberia fundamentalmente promover o aprofundamento do componente disciplinar do saber docente, o que normalmente significa ultrapassar a forma escolar de conhecimento matemático, apresentando ao licenciando a forma 'avançada e profunda' desse conhecimento, ou seja, a Matemática Acadêmica. (MOREIRA; DAVID, 2005, p. 15).

Para romper com a ideia de que somente aquilo ensinado na escola é matemática, necessitamos desenvolver uma consciência docente que reconheça outras formas de matematizar o mundo, diferentes da matemática sistematizada, acadêmica, escolar, não como saberes inferiores, mas como saberes diferentes 
que seguem uma lógica própria que faz sentido no contexto onde foram validados. Isto é importante porque

Desenvolver uma consciência das bases sociais e culturais da Matemática no processo de formação de professores de Matemática é também desenvolver uma consciência de que todos(as) os(as) estudantes têm todo um potencial, embora alguns(mas) pertencentes a certas (sub)camadas culturais ou sociais [...] possam parecer menos capazes. (GERDES, 2010, p. 162).

Isto porque, muitas vezes, é a forma como a prática docente se desenvolve que acaba rotulando os alunos como mais ou menos capazes e isso contribui para a perpetuação de concepções errôneas de que a matemática não é para todos.

A Etnomatemática, na formação de professores, contribui para o alargamento da visão que construímos de matemática, pode ser entendida como uma janela cultural para olharmos a matemática, uma janela que nos permite ver "que em qualquer sociedade, mesmo arcaica, há racionalidade na elaboração de ferramentas, na estratégia da caça, no conhecimento das plantas, dos animais, do solo, ao mesmo tempo em que há mitos, magia e religião" (MORIN, 2000, p. 24) e que essa racionalidade é uma expressão do estabelecimento de relações, de reflexões, do pensamento matemático.

Pensar a Etnomatemática na formação de um professor de matemática não significa negarmos a matemática, mas reconhecermos que a matemática estudada na licenciatura é ela mesma, em suas origens, um compêndio de matemáticas que foram sistematizadas por povos culturalmente distintos. Nessa perspectiva, poderia ser entendida como etnomatemáticas.

Sensibilidade às questões culturais no ensino da matemática não é uma habilidade nata, não é tarefa fácil e precisa ser construída desde a formação inicial do professor, pois a prática docente muito reflete a ambiência na qual somos formados. É necessário, desde a graduação, vivenciarmos situações onde o ensino da matemática dialogue com contextos conhecidos e vividos pelos alunos, contextos capazes de mobilizá-los a aprender num processo do qual são 
protagonistas e o sentido do conteúdo matemático se expanda para além das fronteiras conceituais e disciplinares.

\section{Os caminhos da prática (etno)matemática: viés metodológico}

O Programa Institucional de Bolsas de Iniciação à docência - PIBID possibilita o desenvolvimento de atividades que conciliam teoria e prática inserindo o bolsista no ambiente escolar para que possa construir experiências docentes durante sua formação inicial. Nessa perspectiva, está uma atividade prática que realizamos com um grupo de bolsistas, futuros professores de matemática, em uma escola estadual da cidade de Parintins-AM, cujas ações se fundamentam em ideias etnomatemáticas, ideias que reconhecem que em diferentes contextos há pensamentos que se guiam por lógicas diferentes e se manifestam nos saberes e fazeres das pessoas. (D'AMBROSIO, 2013).

Durante o desenvolvimento do subprojeto Matemática em Foco 2, os bolsistas foram distribuídos nas escolas receptoras e dentre as atividades que realizavam estava o acompanhamento das aulas de matemática ministradas pelo professor supervisor, duas vezes por semana. Decorrente da dinâmica do subprojeto, os espaços de construção de dados, a partir de observações e vivências, constituíram-se das salas de aulas das escolas e o espaço para reflexões foram compostos pelas salas onde ocorriam as reuniões de orientação, na universidade. Os dados produzidos por meio das observações e das vivências eram compartilhados nas reuniões de orientação.

Em uma dessas reuniões entre os bolsistas e uma coordenadora de área, discutimos as principais dificuldades que os alunos expressavam durante as aulas. Um dos bolsistas manifestou preocupação com o fato de ter percebido que os alunos de uma turma de $1^{\circ}$ ano do Ensino Médio não tinham compreendido a definição de Progressão Aritmética (PA) e, constantemente, cometiam erros referentes à identificação da razão da PA quando a questão envolvia um contexto, ou seja, não apresentava a sequência numérica de forma explícita. 
Como coordenadora da reunião e orientadora das aprendizagens dos bolsistas, explicamos que muitas situações podem ser usadas para contextualizar a definição de PA e, no âmbito de vivências de alunos da Região Amazônica, temos a confecção de cestos e paneiros cujo desenvolvimento da trama pode ser representado por uma progressão aritmética (COSTA, 2009). Foi então que um dos bolsistas se manifestou e se apresentou como oriundo de uma comunidade ribeirinha, filho de agricultores que confeccionam paneiros para transportar e armazenar produtos da roça e da pesca.

A partir de então, nossas reflexões direcionaram um olhar crítico para as questões de ensino da matemática e percebemos que esse pode ser um espaço de diálogo, a partir da prática docente, de possíveis relações entre saberes da tradição e saberes escolares tendo consciência que "a fertilidade desse diálogo requer, entretanto, que não se reduza um ao saber do outro, que não se valide um por critérios estipulados pelo outro, uma vez que tratam de estratégias distintas de pensar o mundo" (ALMEIDA, 2010, p. 120).

Como resultado das reflexões, resolvemos realizar uma oficina de ensino de matemática na qual os bolsistas pudessem trabalhar a definição, as características e a determinação da razão de uma PA pelo viés da Etnomatemática, uma vez que, "promove o reconhecimento da existência de outros caminhos para comunicar abstrações do mundo, feitos para sobreviver e transcender nele, além do fornecido historicamente pela matemática disciplinar" (PARRA, 2013, p. 28). Assim, definimos o objetivo da oficina que consiste em propiciar aos futuros professores experiência docente aliada ao diálogo entre saberes da tradição e saberes escolares.

A dinâmica da oficina parte da contextualização cultural de um objeto conhecido pelos alunos para mostrar que no seu processo de confecção está implícita a mobilização de ideias matemáticas entendidas como as "habilidades de classificar, ordenar, inferir, generalizar, medir e avaliar" (D'AMBROSIO, 2013, p. 30), presentes na confecção de um paneiro e que podem ser postas em um diálogo com a representação e os elementos de uma progressão aritmética. 
Inicialmente, na reunião de elaboração da prática (oficina) a ser desenvolvida, pedimos que cada bolsista falasse o que conhecia da vida em comunidades rurais/ribeirinhas. Particularmente, pedimos para que o bolsista que é oriundo de uma comunidade ribeirinha contasse sua experiência com a confecção dos paneiros, falasse sobre a utilidade e o significado desse objeto em sua comunidade. Esse foi um momento de diálogo e compartilhamento de saberes, pois os envolvidos têm raízes amazônicas e, em maior ou menor escala, possuem conhecimentos oriundos do viver rural/ribeirinho onde a confecção e o uso de paneiros adquire significados diferentes dos encontrados na cidade.

Para o trabalho na escola, decidimos, por causa da escassez da matéria prima utilizada na confecção dos paneiros, usar tiras de papel cartão para substituir as talas naturais. Então, com tiras de $1 \mathrm{~cm}$ de largura realizamos o teste da confecção do objeto cultural e a identificação dos objetos matemáticos possíveis de serem contextualizados naquela prática.

A elaboração teórica e metodológica da oficina teve duração de três semanas e exigiu que os bolsistas aprofundassem seus conhecimentos sobre 0 contexto cultural no qual o paneiro surge na vida de comunidades rurais/ribeirinhas. Ademais, o bolsista que era conhecedor do processo de confecção de paneiros compartilhou com todos os membros do grupo sua técnica a fim de que os demais fossem capazes de orientar a atividade que seria realizada com os alunos, na escola. Assim, ampliamos nosso conhecimento de aspectos da cultura ribeirinha e adquirimos noções básicas para a confecção de um paneiro.

Posteriormente, conversamos com o professor de matemática da turma para que ele selecionasse os alunos que apresentavam maiores dificuldades no trabalho com PA. De acordo com a percepção do professor, foram selecionados 12 alunos para participarem da atividade com os bolsistas.

A estratégia adotada para o desenvolvimento da prática foi o trabalho em grupo. Os 12 alunos foram divididos em 3 grupos, ficando cada grupo sob a responsabilidade de um bolsista. O primeiro passo foi estabelecermos um diálogo 
sobre o objeto cultural selecionado: o paneiro. Para tanto, começamos mostrando um paneiro e perguntado se eles conheciam aquele objeto. Os alunos foram unânimes em dizer que se tratava de um paneiro. Nesse momento, expandimos 0 diálogo e abordamos aspectos culturais de grupos que, comumente, confeccionam paneiros na Região Amazônica: os indígenas e os ribeirinhos.

Decorrente do diálogo estabelecido, percebemos que um dos 12 alunos também era oriundo de comunidade ribeirinha e que antes de vir estudar na cidade ajudava o tio a confeccionar paneiros e outros utensílios. Descobrimos que em um dos bairros da periferia, o padeiro utiliza um paneiro para entregar pães nas casas, os alunos lembraram que nas feiras é comum o uso de paneiros e que miniaturas desse objeto são vendidas em lojas de artesanatos como lembranças da região.

O diálogo propiciou uma reflexão sobre o modo de vida em uma comunidade ribeirinha, sobre a percepção da mobilização de ideias matemáticas nas construções, na confecção de artesanatos e utensílios de pesca, na produção de farinha, na cestaria etc.; assim, criamos uma ambiência para ensinar PA estabelecendo relações com saberes desenvolvidos em contextos não acadêmicos, uma ambiência pautada na Etnomatemática que tem como pretensão "a educação multicultural, a qual valoriza e reconhece como legítimo o saber matemático oriundo das diversas culturas ao lado da matemática acadêmica" (ZORZAN, 2007, p.80).

Os dois sujeitos (um bolsista e um aluno da escola) oriundos de comunidade ribeirinha se tornaram importantes interlocutores e descritores dos saberes e dos fazeres, em especial do processo de confecção de um paneiro. Nessa atmosfera, os bolsistas desafiaram e incentivaram os alunos a perceberem ideias matemáticas nos paneiros que ultrapassassem a evidência das formas geométricas.

\section{Os resultados da prática: implicações à formação do professor}


Na perspectiva da Etnomatemática como uma das tendências da Educação Matemática, os cursos de formação de professores podem propiciar o desenvolvimento de práticas pedagógicas que possibilitem ao futuro professor de matemática perceber que partindo de

Situações contextualizadas pelos educandos, a ordem dos conteúdos estabelecidos pelos órgãos oficiais e livros didáticos pode ser alterada. Isso porque os conteúdos, quando trabalhados de forma criativa, permitem aos educadores e educandos um mergulho no oceano da curiosidade. (JUNIOR, 2006, p. 189).

A curiosidade entendida como combustível à aprendizagem deveria permear o ensino da matemática, pois ao longo dos tempos

Há mais invenção do que descoberta nesse denso jogo do rigor no qual o modelo substitui a matéria - quaisquer que sejam as tendências mais ou menos abstratas, empíricas, lúdicas ou sacrais que o tenham motivado no decurso da história. (VERGANI, 2009, p.213, grifos do autor).

O ensino da matemática, no contexto escolar, é por vezes estruturado com base no rigor e no formalismo que nega a imaginação, a criatividade e a contextualização implicando em momentos tensos em vez de construtivos. Nos posicionamos na contramão dessa tensão e partimos da ação criativa dos alunos para o formalismo matemático apregoado nos livros didáticos.

Nessa perspectiva, o roteiro de ensino elaborado visava proporcionar aos alunos o reconhecimento e a valorização dos saberes da tradição, das ideias matemáticas mobilizadas na confecção de paneiros para posteriormente mostrar possíveis relações com os elementos de uma P.A. Assim, no desenvolvimento da oficina, ao percebermos que os alunos não conseguiam elencar ideias matemáticas além das formas geométricas explicitas no objeto, começamos a atividade elaborada. Primeiro, distribuímos uma quantidade de tiras de papelão para cada grupo e orientamos que cada grupo deveria escolher um componente para fazer as anotações. 
Posteriormente, o bolsista que sabe tecer o paneiro começou a explicar como cada grupo deveria ir posicionando as tiras de papel cartão com o objetivo de confeccionarem um paneiro. As orientações dadas foram:

- Escolham duas tiras e as posicionem de forma paralelas sobre a mesa.

- Anotem com quantas tiras vocês começaram a confecção.

- Agora acrescentem mais duas tiras entrelaçando-as de forma oblíqua, acrescentem mais duas tiras na posição diagonal.

A cada passo dado, fazíamos questionamentos do tipo quantas tiras foram acrescentadas? Quantas tiras tem agora? Qual a diferença entre a quantidade anterior de tiras e o total de tiras agora? Que tipo de figura se formou com o entrelaçamento dessas tiras? Decorrente das respostas dadas e da observação das anotações realizadas os alunos perceberam que a confecção de um paneiro pode ser descrita segundo uma P. A de razão dois, pois iniciamos com duas tiras e a cada movimento acrescentamos sempre mais duas tiras que vão dando corpo à trama que está sendo tecida da seguinte forma:

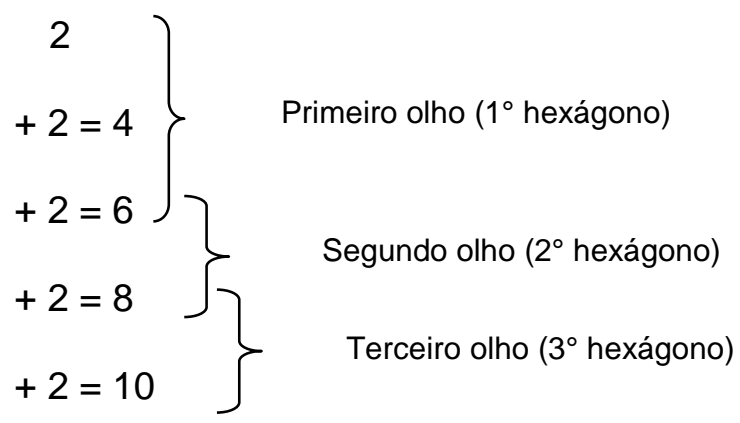

A inserção de tiras de papel segue até a quantidade necessária de acordo com o tamanho do paneiro que queremos confeccionar ou tecer. Nesse processo de confecção, o olho (centro ou umbigo) se constitui em um hexágono vasado e a quantidade de olhos implica na determinação da forma do fundo do paneiro, pois uma quantidade ímpar de olhos determina um fundo redondo e uma quantidade par, um fundo triangular. 
No caso da nossa atividade, trabalhamos com os alunos a confecção de uma miniatura de um paneiro com três olhos, ou seja, com 10 tiras, pois para tecer o primeiro olho utilizamos 6 tiras e para os olhos posteriores foi necessário acrescentarmos apenas mais 2 tiras para cada olho a mais que queríamos confeccionar.

Essa relação nos abriu possibilidade para discutir, além das questões da P.A, elementos da geometria plana como retas paralelas, concorrentes, oblíquas, perpendiculares, formas triangulares, polígonos (paralelogramo, hexágono, losango), lados e vértices. Paralelamente às questões matemáticas estavam as discussões de como se pensa essa confecção no âmbito da vivência em uma comunidade ribeirinha e para tanto, os dois conhecedores (o bolsista e o aluno) se tornaram mediadores do diálogo estabelecido.

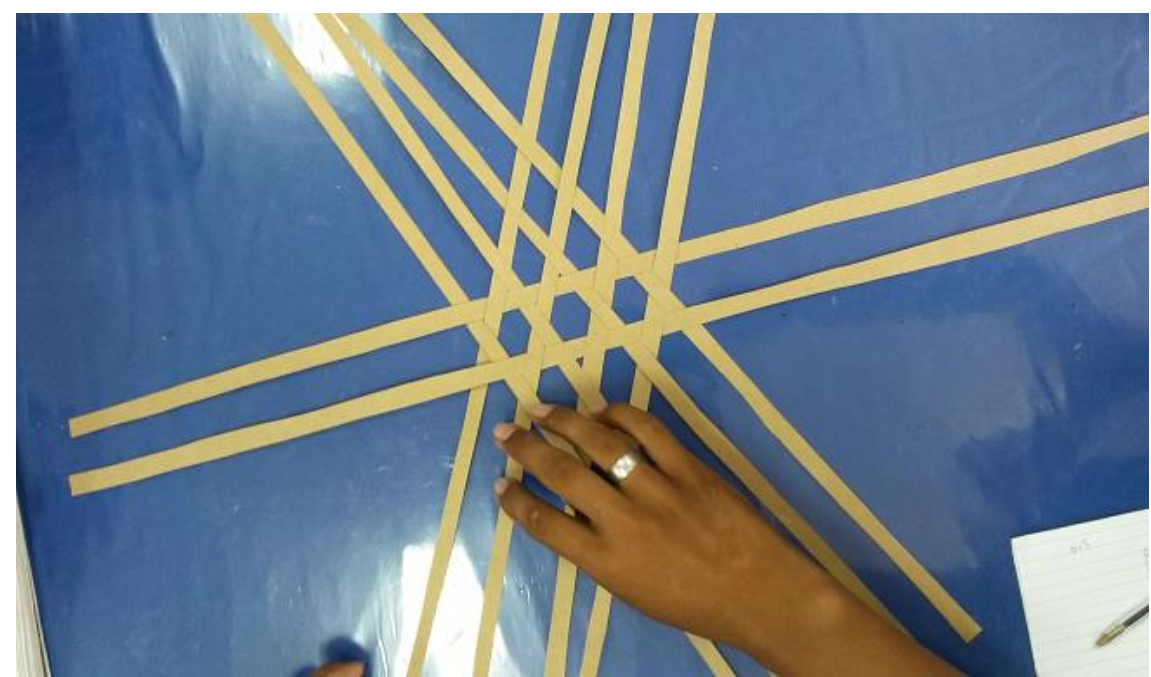

Figura 1 - Os três olhos do paneiro, três hexágonos.

Fonte: Arquivo pessoal dos autores (2017).

Ao longo da atividade, os alunos perceberam que da representação da quantidade de tiras utilizadas na confecção de um paneiro surge uma sequência numérica $(2,4,6,8,10)$ cuja diferença entre a quantidade de tiras, a partir do segundo movimento, sempre é igual a 2. Essa percepção pode ser generalizada ao ponto de os alunos compreenderem a definição de uma progressão aritmética 
finita, pois, na confecção do paneiro, não podemos continuar inserindo tiras infinitamente, isto porque a quantidade de tiras usadas está diretamente relacionada ao tamanho do objeto que queremos confeccionar.

Do diálogo estabelecido, os alunos também perceberam que no momento da confecção, em um contexto fora da sala de aula, não há necessidade de anotar a quantidade de talas ou a forma geométrica que surge, mas há a mobilização de ideias matemáticas manifestadas no ato de observar, comparar, medir, avaliar e inferir, habilidades que direcionam todo o processo e garantem que o conhecimento construído seja repassado a outras gerações.

A compreensão do significado de razão em uma P.A se deu por dedução, ao perceberem que o tecido do paneiro sempre cresce acrescentando-se 2 tiras à trama que já está tecida, de modo que relacionaram razão a crescimento, implicando no reconhecimento de apenas progressões aritméticas crescentes. Nesse momento, por meio de questionamentos, os fizemos perceber que a razão também pode exercer uma função de decrescimento, o que implica no surgimento de uma P.A decrescente. O questionamento principal para essa compreensão foi: imaginem que vocês estão tecendo um paneiro com 18 tiras, com quantas tiras vocês ficariam se tirássemos 2? E se tirássemos 2 novamente? Representem esse movimento de retirada das tiras de papel da trama tecida.

Ao representarem a retirada das tiras obtiveram $(18,16,14,12,10,8,6,4$, 2), uma sequência numérica que decresce segundo uma razão de - 2. A partir da compreensão do que seja uma progressão aritmética e como determinar sua razão foi possível generalizarmos chegando à equação do termo geral.

A seguir, sintetizamos no Quadro 1 os resultados obtidos a partir das relações estabelecidas por meio de uma triangulação entre o objeto cultural (contexto), o objeto matemático e a mobilização de ideias matemáticas, na elaboração, execução, avaliação e reflexão da prática realizada. Evidenciamos que a reflexão sobre a prática se pautou, principalmente, nas ideias de D'Ambrosio (2009, 2012, 2013). 


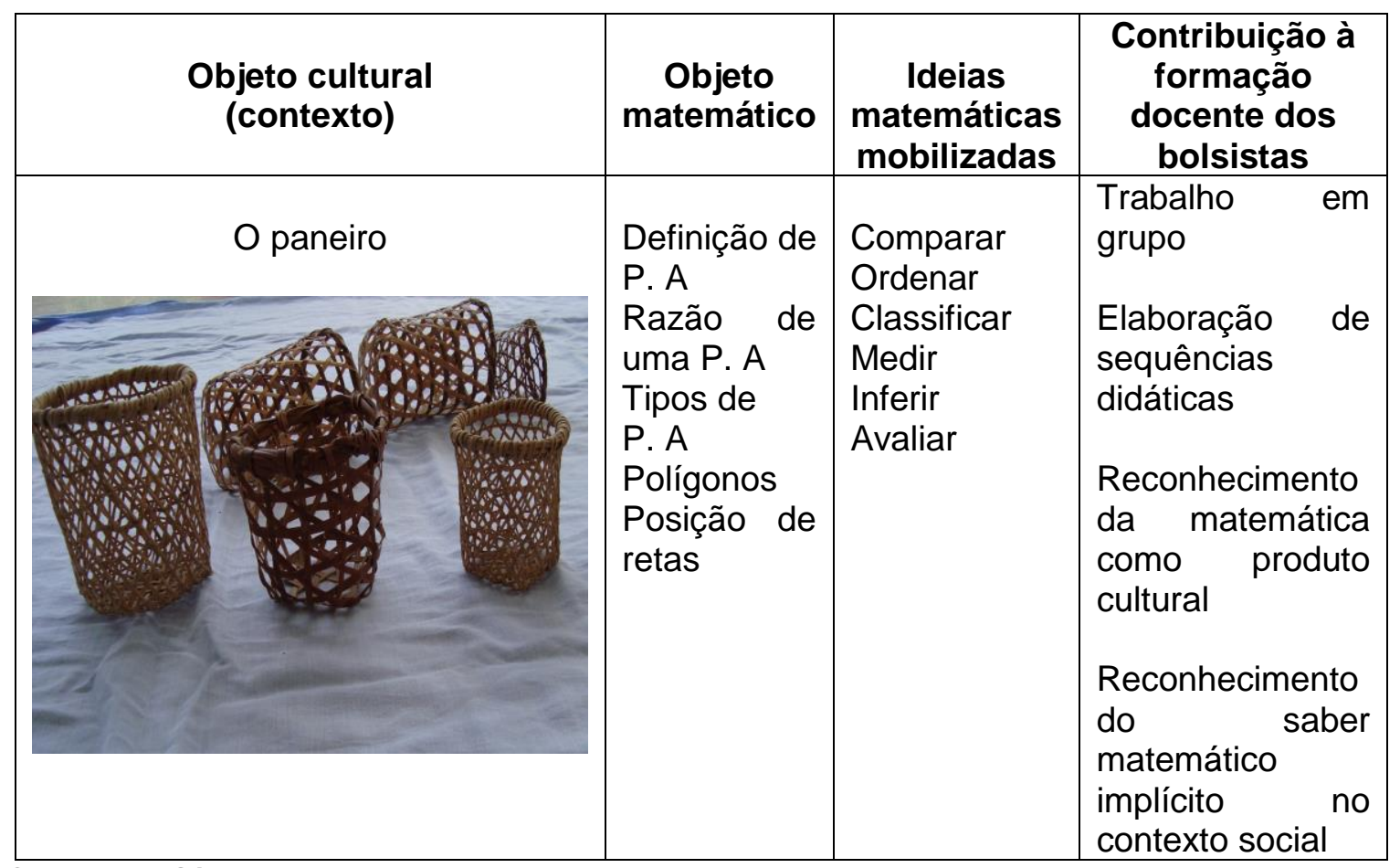

Quadro 1: Síntese dos resultados obtidos

Fonte: Elaboração dos autores

De acordo com as ideias d'ambrosianas, os cursos de formação de professores devem ter o compromisso de proporcionar condições para que os licenciandos possam desenvolver uma visão crítica do ensino da matemática, ampliar o entendimento de docência e a coragem para "ancorar suas teorizações nas suas próprias reflexões práticas" (D’AMBRÓSIO, 2009, p. 81). Decorrente desse entendimento, podemos dizer que os resultados (aprendizagem expressa) tanto pelos alunos da escola quanto pelos bolsistas, só foi possível porque

Acreditamos, com convicção, que o professor e a professora devem tratar a educação escolar pela via de padrões culturais de comportamento e conhecimento, tanto pelo fato de ajudar na atitude mental dos educandos 
frente às relações (matemáticas) que o professor quer desenvolver, quanto por questões de ordem político-social. (DOMITE, 2012, p. 85).

Aceitar, reconhecer e valorizar que padrões culturais de comportamento e conhecimento podem criar e organizar processos intelectuais fora da sala de aula, saberes com outras lógicas, é um exercício que deve ser incentivado durante a formação de um professor de matemática, pois

Está pelo menos equivocado o educador matemático que não percebe que há muito mais na sua missão de educador do que ensinar a fazer continhas ou a resolver equações e problemas absolutamente artificiais, mesmo que, muitas vezes, tenha a aparência de estar se referindo a fatos reais. (D'AMBROSIO, 2013, p. 46).

Nessa direção, as contribuições da prática realizada à formação dos futuros professores de matemática, foram evidenciadas no engajamento dos licenciandos para a realização do trabalho em grupo, na elaboração de sequências didáticas, nos estudos de contextos culturais diversos onde as escolas estão inseridas, no reconhecimento da matemática como produto cultural, no reconhecimento do saber matemático implícito no contexto social. Tais resultados foram compartilhados e serviram de base para a elaboração de um novo subprojeto do PIBID denominado Enlaces Matemáticos, regido pelo Edital ํㅡㄴ 7/2018 da CAPES, que está em desenvolvimento no Centro de Estudos Superiores de Parintins.

A experiência construída aguçou nosso olhar etnomatemático para as diferentes formas de matematizar o mundo, nos fez perceber a necessidade de abrirmos espaço para que o ensino da matemática seja, também, pautado em experiências construídas em contextos culturais, tradicionais ou não, que evidenciam o caráter humano da construção matemática. Percebemos que um ensino nesses termos, desperta o interesse e a atenção dos alunos, inclusive na licenciatura, ajuda-os a estabelecer relações, exercita o pensamento dedutivo 0 que implica na construção, ampliação e/ou transformação da compreensão de objetos matemáticos por meio da reflexão que cada situação apresentada exige. 


\section{Considerações finais}

As reflexões oriundas dos resultados obtidos na realização da atividade apresentada nos permitem dizer que é possível estabelecermos diálogos profícuos entre saberes "matemáticos" validados culturalmente e o ensino de objetos matemáticos presentes no currículo escolar. No entanto, para que a realização de tal diálogo aconteça nas salas de aulas, deve ser incentivada e experienciada durante todo o decurso da Licenciatura em Matemática, pois é nesse processo que o futuro professor se aproximar das diferentes tendências de ensino.

Certamente, há entendimentos diferentes do que seja uma prática etnomatemática no âmbito das tendências da Educação Matemática, mas na linha de convergência está o posicionamento docente cujas práticas de ensino não se guiam exclusivamente por uma ideia essencialista e estruturalista da matemática.

Assim, a prática descrita se constituiu uma ação formativa com intenções etnomatemáticas ao possibilitar que os futuros professores pudessem reconhecer, dar visibilidade e incentivar a valorização de uma prática cultural na qual podemos vislumbrar a possibilidade de diálogo entre os saberes da tradição e os saberes curriculares da matemática escolar, um diálogo onde nenhum saber se sobrepõe ao outro, ao contrário, se complementam e dão sentido ao objeto matemático em estudo.

É importante salientar que nossa intenção não foi e nunca será dar uma receita mágica para eliminar as dores das dificuldades de aprendizagem em um determinado conteúdo matemático, mas de divulgar um olhar diferenciado para a forma de ensinar contextualizando o objeto matemático em uma realidade próxima daquela vivida por quem ensina e pelos alunos.

A confecção de paneiros é uma atividade cultural amazônica, ribeirinha e indígena, seu produto é conhecido e utilizado nas cidades do interior do Amazonas. Nesse estado brasileiro muitas pessoas que vivem nas cidades, também, são conhecedoras desse processo porque aprenderam com seus familiares quando viviam em ambiente rural/ribeirinho, conhecem a utilidade de 
um paneiro para comunidades que têm na agricultura, no extrativismo ou na pesca, fonte de sustento. Então, a confecção de um paneiro pode ser um contexto para o ensino de conteúdos matemáticos que encontrem possibilidades de diálogos com as ideias matemáticas mobilizadas nesse processo.

Nessa direção, a prática realizada articulou-se com a Etnomatemática ao possibilitar que os bolsistas refletissem, investigassem e adquirissem conhecimentos "matemáticos" que são construídos fora da escola, com um forte caráter cultural, para daí pensarem na integração e incorporação desses conhecimentos em suas práticas docentes no contexto escolar. Fato que no nosso entendimento, a partir da fundamentação teórica utilizada, é essencial nos cursos de formação de professores de matemática, pois a ação pedagógica começa a ganhar forma ainda na graduação. Daí depreende-se que se formos formados em uma ambiência que desconheça a possibilidade de diálogo entre saberes da tradição e saberes escolares, ditos científicos, dificilmente acreditaremos e teremos uma prática pedagógica etnomatemática, qualquer que seja sua concepção.

\section{Referências}

ALMEIDA, Maria da Conceição de. Complexidade, saberes científicos, saberes da tradição. São Paulo: Livraria da Física, 2010.

COSTA, Lucélida de Fátima Maia da Costa. A etnomatemática na educação do campo, em contextos indígena e ribeirinho, seus processos cognitivos e implicações à formação de professores. Dissertação (Mestrado em Educação em Ciências na Amazônia) - Universidade do Estado do Amazonas, Manaus, 2012.

D’AMBROSIO, Ubiratan Etnomatemática: elo entre as tradições e a modernidade. Coleção tendências matemáticas. Belo Horizonte: Autêntica editora, 2013.

D'AMBROSIO, Ubiratan. Educação Matemática: da teoria à prática. São Paulo: Papirus, 2009.

D’AMBROSIO, Ubiratan. Do Saber Matemático ao Fazer Pedagógico: o desafio da educação. Revista Educação Matemática em Foco, v. 1, n.1, p. 53-64, jan/jun, Campina Grande: EDUEPB, 2012.

D’AMBROSIO, Ubiratan. Etnomatemática: elo entre as tradições e a modernidade. Belo Horizonte: Autêntica, 2013. 
DOMITE, Maria do Carmo Santos. Acertando o passo do movimento entre etnomatemática, formação de professores e aprendizagem da matemática: pré-requisito dos alunos e escuta dos professores em discussão. Revista Educação Matemática em Foco, v. 1, n.1, p. 83-96, jan./jun, Campina Grande: EDUEPB, 2012.

FIORENTINI, Dario. Alguns modos de ver e conceber o ensino da matemática no Brasil. Zetetiké - Cempem - FE - Unicamp - ano 3, n. 4, 1995.

GERDES, Paulus. Da etnomatemática a arte-design e matrizes cíclicas. Belo Horizonte: Autêntica, 2010.

JUNIOR, Gilberto Chieus. Etnomatemática: reflexões sobre a prática docente. In: RIBEIRO, J. P. M.; DOMITE, M. C. S.; FERREIRA, R. (Orgs). Etnomatemática: papel, valor e significado. Porto Alegre: Zouk, 2006.

LUCENA, Isabel Cristina Rodrigues de. Etnomatemática e transdisciplinaridade: a propósito do GEMAZ. In: MENDES, I. A.; LUCENA, I. C. R. de. (Orgs). Educação Matemática e cultura Amazônica: fragmentos possíveis. Belém: Editora Açaí, 2012.

MOREIRA, Plínio Cavalcante; DAVID, Maria Manuela M.S. A formação matemática do professor: licenciatura e prática docente. Belo Horizonte: Autêntica, 2005.

MORIN, Edgar. Os sete saberes necessários à educação do futuro. Edgard de Assis Carvalho. São Paulo: Cortez; Brasília, DF: UNESCO, 2000.

PARRA, Aldo. Linguagem escrita e matemática: Um Viés Etnomatemático. Revista Latinoamericana de Etnomatemática, v. 6, n 2, p. 24-34, 2013.

SOUZA, José Camilo Ramos de; COSTA, Lucélida de Fátima Maia da; ALMEIDA, Regina Araújo de. Etnomatemática transversalizando temas cotidianos. In: COSTA, L. F. M. de.

(Org). Etnomatemática e Educação Matemática: saberes de um itinerário amazônico. Manaus: BK editora, 2011.

TAVARES, Nathália Pereira; COSTA, Lucélida de Fátima Maia da. Estágio Supervisionado e Etnomatemática na formação do professor de matemática. In: ENCONTRO PARAENSE DE EDUCAÇÃO MATEMÁTICA, 10., 2015, Belém. Anais... Belém: SBEM-PA, 2015.

VERGANI, Teresa. Matemática, poesia, magia: a propósito da inteireza relacional conhecimento/vida. In: FARIAS, C. A.; MENDES, I. A.; ALMEIDA, M. C. de. (Orgs). A criatividade como destino: transdisciplinaridade, cultura e educação. São Paulo: Livraria da Física, 2009.

ZORZAN, Adriana Salete Loss. Ensino-aprendizagem: algumas tendências na educação Matemática. Revista Ciências Humanas, v. 8, n¹0, p. 77- 93, Jun, 2007. 